\title{
Tv Globo e Globo Filmes: práticas econômicas e relações com o Estado a partir de perspectivas da indústria cultural e hegemonia
}

\author{
Dostoiewski Mariatt de Oliveira ChampangnatTe \\ Doutor em Educação (Universidade do Estado do Rio de Janeiro) \\ Professor da Universidade do Grande Rio \\ dostoiewski.tico@gmail.com
}

\begin{abstract}
Resumo O objetivo desse artigo é analisar algumas práticas da Tv Globo e da Globo Filmes, braços de TV e cinema da Rede Globo, a partir dos conceitos de indústria cultural, hegemonia e aparelho privado de hegemonia. Quanto à Tv Globo, traça-se um panorama histórico para analisar suas estratégias econômicas, que a possibilitam ser uma indústria cultural hegemônica, como para discutir suas relações com o Estado, fatos esses que tornam possível sua caracterização como aparelho privado de hegemonia. Quanto à Globo Filmes, discutem-se suas estratégias relacionadas à produção e à distribuição filmica nacional que objetivam torná-la hegemônica no que diz respeito à atividade cinematográfica brasileira contemporânea.
\end{abstract}

Palavras-chave: Tv Globo; Globo; Filmes; Indústria Cultural; Hegemonia; Aparelho Privado de Hegemonia.

\section{Introdução}

$\mathrm{O}$ PRESENTE ARTIGO tem como objetivo analisar algumas práticas da TV Globo e da Globo Filmes, respectivos braços de televisão e cinema da empresa de comunicação Rede Globo, a partir dos conceitos de indústria cultural, hegemonia e aparelho privado de hegemonia. Inicialmente, tais conceitos são apresentados e, após, há a construção de um panorama histórico de importantes ações mercadológicas da TV Globo e suas relações com o Estado. Em seguida, passa-se para a discussão de práticas da Globo Filmes no intuito de compreender sua hegemonia no que diz respeito à atividade cinematográfica brasileira contemporânea ${ }^{1}$.

Um meio de comunicação, segundo Coelho (1980), tem a função básica de transmitir informações, sejam reais ou inventadas. No entanto, essa função permite que um meio de comunicação seja protagonista de mudanças econômicas, políticas e sociais. Para isso, ele precisa alcançar uma grande quantidade de pessoas, contribuindo para a formação de opiniões e tomadas de decisão. Um meio de comunicação que alcança esse patamar pode ser chamado de meio de comunicação de massa e

1 Esse artigo é resultado de uma pesquisa realizada durante o curso de doutorado do presente autor e algumas de suas partes fazem parte de sua tese de doutorado. 
seu funcionamento baseia-se na transmissão de informações, de forma homogênea, para grandes públicos. Em sociedades onde há meios de comunicação de massa com grandes abrangências e influências sociais, há a formação de culturas de massa fortemente ligadas aos interesses econômicos e ideológicos dos próprios meios.

A análise dos meios de comunicação e da cultura, pela perspectiva massificadora dos primeiros, foram as bases para Adorno e Horkheimer criarem o conceito de indústria cultural. Esta ideia aparece pela primeira vez na obra Dialética do esclarecimento (1985), que teve sua primeira edição lançada em 1944, e foi resultado de pesquisas realizadas pelos autores sobre o rádio e o jornal impresso nos Estados Unidos. Ortiz (1986) aponta que o conceito sintetiza a crítica à cultura das sociedades modernas e às práticas dos meios de comunicação.

O conceito de indústria cultural tem como abordagem básica a caracterização de um meio de comunicação de massa como uma indústria qualquer, em que o objetivo principal é o lucro advindo da venda e consumo de seus produtos, nesse caso chamados de produtos culturais. Adorno e Horkheimer (2009) afirmam que, pelo fato de uma indústria cultural atuar diretamente na cultura, ela trabalha sua própria imagem a partir do mascaramento do objetivo principal, o lucro, como se suas práticas existissem para o bem social, desatreladas de interesses econômicos.

Os comportamentos dos espectadores, os consumidores da indústria cultural, são moldados por estratégias de negócios que visam à fidelização desses e ao estabelecimento de parcerias estratégicas com outras empresas interessadas em tomar tais espectadores como consumidores de seus produtos e serviços. Ou seja, de acordo com Adorno e Horkheimer (2009), as escolhas de conteúdos trabalhados por uma indústria cultural não são aleatórias e obedecem aos seus posicionamentos de negócios e aos interesses de seus parceiros econômicos que, afinal, são quem, basicamente, sustentam toda a indústria a partir de ações publicitárias.

A grande força de uma indústria cultural está relacionada à sua capacidade de criar/fomentar uma cultura de massa diretamente atrelada a seus interesses. Essa estratégia fica mais forte quando uma indústria cultural atua em diferentes meios de comunicação de massa, como a televisão, o jornal impresso e o rádio atingindo, assim, uma grande quantidade de espectadores. E, mesmo utilizando linguagens diversas e dirigindo-se a públicos distintos, todos os meios obedecem a um mesmo viés ideológico estabelecido pelos gestores principais da indústria cultural.

O viés ideológico de uma indústria cultural tem como premissa básica o lucro e, como já dito, isso é buscado a partir de parcerias econômicas com outras empresas. No entanto, tais parcerias podem ocorrer com o Estado,. Nessa instância, pode haver investimentos financeiros diretos ou a formulação/alteração de políticas/legislações, por parte do Estado, que beneficiem determinada indústria cultural que, por sua vez, em contrapartida, direcionará positivamente a abordagem midiática relacionada ao Estado.

Nesse sentido, as relações da indústria cultural com outras empresas e com o Estado as tornam complexas estruturas sociais que, como já dito, vão formar e interferir na cultura de massa. A partir disso, busca-se o conceito de aparelho privado de hegemonia para se vislumbrar a complexidade do funcionamento das indústrias culturais. Tal conceito foi criado por Gramsci (2001) e refere-se a empresas, ou organizações privadas que mantém relações/parcerias com o Estado buscando, juntamente com esse, o consenso de posicionamentos ideológicos que permeiam programas e estratégias políticas e econômicas. A imprensa, via rádio, televisão ou internet, pode funcionar como um aparelho privado de hegemonia, pois, através dela, fatos são noticiados e a escolha/construção de tais notícias pode trazer consigo posicionamentos ideológicos e interesses comungados pelo Estado, por empresas privadas parceiras e pela própria imprensa. Nesse sentido, a imprensa, então, exerceria a função de informar e de contribuir para convencer e hegemonizar valores a partir das notícias que veicula e das formas como as elabora e expõem ao público.

Essa busca de consenso junto ao público refere-se ao conceito de hegemonia, criado também por Gramsci, e que, segundo Moraes pode ajudar "a desvendar os jogos de consenso e dissenso que atravessam e condicionam a produção simbólica nos meios de comunicação, interferindo na conformação do imaginário social e nas disputas de sentido e de poder" (2010, p.54). Gruppi afirma que a hegemonia "é concebida como direção e domínio e, portanto, como conquista, através da persuasão, do consenso" (1978, p. 58). Nesse sentido de conquista/persuasão, Gramsci afirma que "toda relação de 'hegemonia' é necessariamente uma relação pedagógica” (1999, p.399). Ou seja, a conquista, a persuasão e a busca de consenso podem ser percebidas como estratégias pedagógicas para o estabelecimento da hegemonia por parte de determinada classe dominante. Em termos da hegemonia de uma indústria cultural, essa vai utilizar-se de sua condição de aparelho privado de hegemonia para articular processos estratégicos na busca de consensos para seu crescimento e a manutenção hegemônica de suas ideologias e atividades.

Após essa breve apresentação dos conceitos de indústria cultural, de aparelho privado de hegemonia e de hegemonia, passa-se para a discussão de algumas práticas da $T V$ Globo e Globo Filmes, com o objetivo de vislumbrá-las a partir desses conceitos. Inicialmente, traça-se um breve panorama do desenvolvimento de indústrias culturais no Brasil, salientando o nascimento/trajetória da $T V$ Globo e suas relações com o Estado. 


\section{TV Globo - análises de práticas de uma indústria cultural e de um aparelho privado de hegemonia}

Em relação ao desenvolvimento da indústria cultural no Brasil, Duarte (2012) afirma que essa demorou um pouco a acontecer. No início do século XX, já havia jornais impressos presentes nos grandes centros, no entanto, não eram tão de grande porte ao ponto de se enquadrarem no conceito de indústria cultural. Além disso, a penetração popular de tais jornais era dificultada pela alta taxa de analfabetismo no Brasil que, segundo o INEP (2003), era de 65\% de 1900 até 1940. Porém, esses jornais já eram empresas e, como afirma Sodré (1999, p. 276), havia também aqueles de "virulenta oposição, confrontando com os jornais que se subordinavam ao poder".

O início da atividade radiofônica, no Brasil, em meados dos anos 1920, foi marcada por dificuldades que se referem a dois fatores principais, segundo Calabre (2002): a não existência de anunciantes que sustentassem as emissoras que surgiam e o pouco número de aparelhos receptores, que eram caros e, assim, dificultavam a aquisição por futuros ouvintes. A forma encontrada para manter uma emissora foi a formação de rádios-sociedades, na qual associados colaboravam com quantias mensais. "A verba arrecadada dessa forma era a principal, senão a única, fonte de renda das emissoras" (p.12). Tal estruturação, associada aos altos preços dos aparelhos receptores, vinculou a atividade radiofônica às elites, no início da década de 1920.

Ainda segundo Calabre (idem), a passagem dessa fase para uma exploração comercial do rádio se deu a partir de alguns acontecimentos no final da década de 1920, como as investidas de empresas de aparelhos receptores de rádio, por exemplo, a General Eletric, que passou a baratear seus aparelhos e a estimular as pessoas a comprarem. A chegada de agências de propaganda americanas, como a Thompson e a McCann-Erickson, e a importação de modelos e formatos de anúncios específicos para rádio, como spots e jingles ${ }^{2}$; o que contribuiu para melhorar a confiabilidade do rádio junto a anunciantes. E a popularização da programação, por parte das emissoras, com o objetivo de atrair novos ouvintes e mais patrocinadores. Soma-se a isso, também, segundo Haussen as "grandes transformações em toda a sociedade brasileira, com o aumento da população, o crescimento dos centros urbanos e o desenvolvimento da indústria e dos serviços" (2004, p.52), a partir das décadas de 1930 e 1940, que contribuíram, também, para que o rádio se consolidasse como um forte meio de entretenimento para a população urbana, principalmente.
No final da década de 1920 e na década de 1930, segundo Hupfer (2009), surgiram importantes emissoras de rádio que logo alcançariam projeções nacionais, como a Rádio Record, fundada em 1928; a Rádio Tupi, em 1935 e a Rádio Nacional, fundada em 1936 pela iniciativa privada e incorporada pelo Estado, por Getúlio Vargas, em 1940. Com a expansão das emissoras é que se pode começar a visualizar a estrutura ou o funcionamento de um meio de comunicação de massa no Brasil. Tal como Calabre (2002), Hupfer (idem) também afirma que o sucesso das emissoras de rádio teve grande influência da popularização de suas programações, que passaram a incluir radionovelas e programas musicais de auditório.

Os programas de auditório tinham, como atração principal, a apresentação de cantores e cantoras que fizeram muito sucesso, tal como Orlando Silva, Carlos Garlhardo, Marlene, Emilinha Borba e Carmen Miranda. Entre os programas de maior sucesso, pode-se citar o Programa Casé, "que passou por sete emissoras cariocas em seus quase vinte anos no ar, mas teve seu período áureo durante oito anos na Mayrink Veiga, na década de 1940" (Saroldi, 2003, p.54). As rainhas do rádio, como eram chamadas as principais cantoras, tornaram-se produtos culturais chefes das emissoras. Juntamente com elas, faziam-se parcerias comerciais com gravadoras de discos e empresas de propaganda, vendendo-as como garotas-propaganda, e também com estúdios de cinema, em que essas "rainhas" estrelavam filmes nacionais e até internacionais, como aconteceu com Carmen $\mathrm{Mi}$ randa (Hupfer, 2009). Tais rainhas foram grandes protagonistas da era de ouro do rádio brasileiro, período que abrange a segunda metade dos anos 1930 até o final da década de 1950, quando a televisão começou a crescer em termos de audiência e investimentos publicitários (Calabre, 2002).

O início da história da televisão no Brasil, segundo Barbosa (2010), pode ser percebido a partir de anúncios publicitários e matérias de jornais e revistas que falavam sobre a televisão anos antes da primeira transmissão no país, patrocinados pela General Eletric, contribuindo para a "formação de um imaginário tecnológico sobre a televisão" (p.16). A investida da General Eletric estava diretamente relacionada às estratégias de construção das primeiras emissoras de televisão brasileiras, por Assis Chateaubriand, um dos proprietários da rádio e jornal impresso Diários Associados. Barbosa (idem) aponta que além do estreitamento com a empresa de aparelhos de TV citada, Chateaubriand também realizou parcerias econômicas com outras empresas para que o financiamento das duas primeiras emissoras, TV Tupi Difusora São Paulo e TV Tupi Rio, pudesse ocorrer. Na cerimônia de inauguração da TV Tupi Difusora São Paulo, em 18 de setembro de 1950, Assis Chateaubriand ressaltou 
a importância dos patrocinadores na empreitada pela televisão, evidenciando a estreita ligação que os anunciantes já tiveram e teriam com esse novo meio de comunicação.

O empreendimento da televisão no Brasil, em primeiro lugar, devemo-lo a quatro organizações que, logo, desde 1946, se uniram aos Rádios e Diários Associados para estudá-lo e possibilitá-lo neste país. Foram a Companhia Antarctica Paulista, a Sul América Seguros de Vida e suas subsidiárias, o Moinho Santista e a Organização Francisco Pignatari. Não pensem que lhes impusemos pesados ônus, dado o volume da força publicitária que detemos (Barbosa, 2010, p.18) .

A programação inicial da televisão foi composta por adaptações de formatos do rádio. Os programas de auditório passaram a ser filmados. As radionovelas viraram telenovelas, mas com poucos capítulos e de curta duração. Outro ponto importante para a compreensão do início da produção televisiva no Brasil é o fato de ela ter sido feita ao vivo nos seus quatorze primeiros anos de existência. Não havia equipamentos para gravar e editar, apenas para transmitir. Esse fator limitava a produção de programas em grande escala, de longa duração ou que se utilizassem de gravações externas. Portanto, a programação não tinha muita variedade, além de não ser contínua. Todas essas características, somadas ao fato de um equipamento de televisão, na década de 1950 e no início dos anos 1960, ser caro e restrito às elites econômicas, descaracterizam a televisão como um meio de comunicação de massa no Brasil nesse período (Ribeiro; Roxo; Sacramento, 2010; Ortiz, 1986).

Em 1964, chega ao Brasil a tecnologia do videotape, com câmeras que possuíam fitas, nas quais a programação poderia ser gravada, e ilhas de edição, onde a gravação poderia ser editada. Segundo Alencar (2004) 4 e Ribeiro, Roxo e Sacramento (2010), esse avanço tecnológico permitiu às emissoras maior liberdade para produzir seus programas e, consequentemente, mais qualidade no que era exibido. As novelas não precisavam mais ser ao vivo. Os atores poderiam errar, vários cenários poderiam ser construídos, e gravações externas poderiam ser feitas de forma independente.
Contemporâneo a isso, houve também uma modernização dos aparelhos de televisão, acompanhada de um barateamento de seus custos para o consumidor final, aumentando o número de lares que possuíam o aparelho.

Em 1965, é inaugurada a TV Globo, pelo jornalista Roberto Marinho, proprietário de uma emissora de rádio de mesmo nome e do jornal impresso O Globo, no Rio de Janeiro. Alencar (2004) afirma que a $T V$ Globo demorou apenas cinco anos para ser a emissora de TV líder em audiência no país, atribuindo isso a diversos fatores. $O$ primeiro se refere ao fato de a $T V$ Globo ter surgido já utilizando a tecnologia do videotape, o que possibilitou liberdade de criação artística e de produção desde seu início. Outro fator se refere às estratégias de expansão da emissora pelo país, por meio de parcerias com diversas televisões locais ${ }^{5}$, para que reproduzissem a sua programação, posicionamento adotado ainda nos anos 1960. Um terceiro fator está relacionado com a estratégia de gestão da sua grade de programação, voltada para torná-la mais atraente aos olhos dos investidores, ou seja, para angariar mais publicidade. Além disso, Alencar (2004) atribui o sucesso da TV Globo ao papel desempenhado por seus dois gestores principais na época: Walter Clark e José Bonifácio Oliveira Sobrinho, o Boni' .

Walter Clark, em seu livro O campeão de audiência (1991), explica como implementou uma grade de programação na $T V$ Globo que atraiu uma vasta demanda de anunciantes. A estratégia consistiu em segmentar o público por meio do agrupamento de programas com público-alvo semelhante, levando-se em consideração uma faixa de horário adequada. Por exemplo, no período vespertino, que tinha mulheres donas de casa como maioria do público, eram transmitidos programas que a emissora julgava ser do interesse delas, como programas de receitas culinárias e curiosidades domésticas. Em outro exemplo, no período noturno, em que os homens já chegaram do trabalho, haveria programas e novelas com temas relacionados a eles. Mesmo que toda a família também assistisse, geralmente era o homem quem determinava o que se via na TV quando estava em casa (Clark, 1991).

Essa estratégia de segmentação de público, atrelada ao tipo de programação exibida, também aparece em

3 Discurso de Assis Chateaubriand durante inauguração da TV Tupi Difusora de São Paulo, disponível em

<http://www.telehistoria.com.br/canais/emissoras/tupi/tupi5.htm>

4 Mauro Alencar é pesquisador contratado pela TV Globo e, em seu livro A Holywood brasileira - panorama da telenovela no Brasil (2004), aborda, como já diz o título, a história da telenovela no país, desde a primeira novela "não diária", Sua vida me pertence, em 1951, produzida TV Tupi de São Paulo, até o início dos anos 2000.

5 Essas parcerias resultaram no que se chama hoje de emissoras de televisão afiliadas da TV Globo, prática que foi/é exercida também por outras emissoras, como SBT, Record e Band (Alencar, 2004).

6 O Boni, José Bonifácio de Oliveira Sobrinho, lançou uma biografia em 2011. Nela, ele afirma que a informação do livro de Walter Clark, onde ele diz que foi ele quem criou a grade de programação, é falsa. Na verdade, ele e Walter Clark só fizeram copiar o modelo americano. Cópia ou não, a estratégia deu certo (Roberto Ramos, 2005). 
Alencar (2004) em que ele explica que os temas das novelas eram adaptados de acordo com seus horários e públicos-alvo. A novela das $18 \mathrm{~h}$ era voltada para a dona de casa e contou com muitos enredos de época baseados em romances da literatura brasileira, como "Helena, Senhora, A Moreninha, O feijão e o sonho, passando por Escrava Isaura, Dona Xepa, Cabocla", dentre outras (p. 28). Ela era voltada para a dona de casa que estaria "em casa" esperando o esposo e os filhos chegarem, preparando o jantar. "O horário das 19 horas estabeleceu-se com as comédias de costumes, dirigidas para o público jovem" (p. 29). Neste horário, os filhos já estariam em casa e poderiam assistir a novelas, tais como "Estúpido cupido e Locomotivas". "O horário das 20 horas abordava temas rurais e urbanos e o horário das 22 horas exibia temas adultos". Esses dois horários tinham como público-alvo o homem adulto pai de família (p.29).

A programação segmentada por diversos tipos de público-alvo permitia a negociação dos espaços publicitários de forma mais determinada e rápida, pois um anunciante poderia visualizar em qual horário seu público-alvo estava vendo televisão e investir de maneira mais objetiva. Além da segmentação, essa programação era fixa, ou seja, tanto o espectador quanto o anunciante sabiam quais dias da semana e em quais horários seus programas de interesse eram exibidos. Para não prejudicar determinados horários e programas, devido a uma possível falta de interesse por parte dos anunciantes, os executivos da $T V$ Globo decidiram começar a "vender pacotes de horários, de maneira tal que quem quisesse anunciar no horário nobre teria que anunciar também em outros horários" (Alencar, 2004, p. 55).

Alencar, após apresentar as notáveis estratégias que levaram a $T V$ Globo a ser líder de audiência no início dos anos 1970, cita que a Rede Globo teve uma sociedade com a Time-Life, um grupo americano de comunicação, iniciada em $1962^{7}$. Graças a essa sociedade, obtiveram-se consultorias de executivos e profissionais técnicos e artísticos, sendo que:

quando o grupo Time-Life se desassocia da Rede Globo, em 1969, a emissora já havia tido condições de se estruturar, aprendendo com os executivos do grupo americano a organizar uma empresa que trata a cultura como produto dentro de um mercado cultural de massa (Alencar, 2004, p. 55).
Essa colocação de Alencar é importante em dois pontos para este trabalho. O primeiro está relacionado ao fato de a Rede Globo ter como estratégia se tornar um meio de comunicação de massa, visando tratar a cultura como um "produto" para um "mercado cultural de massa". Nesse sentido, ela busca, na perspectiva dos executivos americanos, país onde a televisão já fazia parte da indústria cultural, experiências e ensinamentos para se tornar uma indústria cultural no Brasil.

O outro ponto está relacionado à questão do tipo de envolvimento que ocorreu entre a $T V$ Globo e o grupo Time-Life. Na época da assinatura da parceria, em 1962, estava em vigência a Constituição de 1946, cujo Artigo $160^{8}$ proibia empresas estrangeiras de investir capital ou ser donas/sócias de empresas de comunicação no Brasil. Em 1965, dois meses após a inauguração da TV Globo, Carlos Lacerda, governador do Estado da Guanabara, denunciou como ilegal a relação da Time-Life com a Rede Globo. A denúncia afirmava que essa recebera cerca de cinco milhões de dólares do grupo Time-Life para desenvolver a estrutura de sua televisão e que, em troca, o grupo americano ficaria com 30\% de seus lucros (ROBERTO RAMOS, 2005). Alencar (2004, p. 56) apresenta um trecho de uma entrevista concedida por Walter Clark, em que esse defende a TV Globo ao afirmar que "o dinheiro do grupo Time-Life não existia, o grupo garantia apenas uma assessoria técnica”.

A possível relação ilegal entre as duas empresas foi para o Congresso Nacional, onde se instituiu uma Comissão Parlamentar de Inquérito (CPI). Ela concluiu que o acordo era inconstitucional. Entretanto, "o presidente Castelo Branco alterou a Constituição para legalizar o acordo Globo/Time-Life em 1967" (Roberto Ramos, 2005, p. 144).

Alencar (2004), como já dito em nota de rodapé, é pesquisador da $T V$ Globo e, portanto, mantém o seu discurso como o da própria empresa. No site oficial chamado Memória Globo ${ }^{9}$, produzido pela TV homônima, há uma matéria sobre o caso Time-Life. Nela há o relato de que o parecer da CPI foi negativo à emissora, mas que, em 1967, houve uma mudança "efetiva" na lei e, como descrito no site, esta "tratava-se de um dispositivo legal sem efeito retroativo, e os contratos do Time-Life com a TV Globo eram de 1962 a 1965”. Portanto, não haveria punição a ela.

Roberto Ramos (2005) aponta como grave tal atitude do Presidente Castelo Branco. Para entendimento

7 Aqui, quando se fala em Rede Globo, estão inclusos os meios de comunicação agregados: televisão, rádio e jornal impresso. O acordo com o grupo Time-Life ocorreu em 1962, envolvendo o rádio e o jornal impresso e preparando a Rede Globo para construir a TV Globo, inaugurada em 1965. 80 Artigo 160 da Constituição de 1946 diz que "É vedada a propriedade de empresas jornalísticas, sejam políticas ou simplesmente noticiosas, assim como a de radiodifusão, a sociedades anônimas por ações ao portador e a estrangeiros. Nem esses, nem pessoas Jurídicas, excetuados os Partidos Políticos nacionais, poderão ser acionistas de sociedades anônimas proprietárias dessas empresas. A brasileiros (art. 129 , nº s I e II) caberá, exclusivamente, a responsabilidade principal delas e a sua orientação intelectual e administrativa". Disponível em: http://www.jusbrasil.com.br/topicos/10613660/artigo-160-da-constituicao-federal-de-18-de-setembro-de-1946 
de tal proposição, é necessário situar que este fora um presidente da ditadura militar brasileira e que tal mudança na lei, favorecendo a TV Globo, resultou em trocas de favores entre a ditadura e a emissora. Um exemplo desses favores era o fato de os jornais da Rede Globo ignorarem, não noticiando, desaparecimentos e torturas de perseguidos políticos, como também greves e conflitos no país, como exemplifica Roberto Ramos (2005, p. 144), a partir de uma fala do Presidente Médici:

Sinto-me feliz, todas as noites, quando ligo a televisão, para assistir ao jornal. Enquanto as notícias dão conta de greves, agitações, atentados e conflitos em várias partes do mundo, o Brasil marcha em paz, rumo ao desenvolvimento. É como se eu tomasse um tranquilizante, após um dia de trabalho.

Os jornais da Rede Globo, em todos os seus meios - impresso, rádio e televisão - exaltavam feitos governamentais, como obras e avanços na economia, praticamente ignorando a existência de um regime repressor e fazendo valer a troca de favores. Essa parceria entre Rede Globo/TV Globo e o Estado a caracteriza como um aparelho privado de hegemonia, a partir do que foi apontado sobre esse conceito. E, a seguir, outros envolvimentos desse meio de comunicação com o Estado são discutidos, reiterando, ainda mais, tal caracterização.

Logo no governo de José Sarney, 1985-1990 - primeira gestão civil após anos de ditadura militar a Rede Globo já alterou sua estratégia e passou a apoiar tal regime, ainda mais que o Ministro de Comunicação desse governo foi Antônio Carlos Magalhães, dono da TV Bahia, afiliada da TV Globo nesse Estado, a partir de 1987. Segundo Pieranti (2006), Antônio Carlos Magalhães liberou diversas concessões públicas de rádio e televisão para políticos, utilizando-se disso como barganha, principalmente, para pleitear a aprovação do mandato de Sarney de quatro para cinco anos, no ano de 1988. A Rede Globo apoiou tais feitos, de forma indireta, ao não chamar a atenção para as práticas de seu parceiro Ministro e se beneficiou com afiliações de novas concessões de rádio e TV para sua própria rede.

Outro momento importante de envolvimento da $T V$ Globo com o Estado foram suas relações díspares com o político Fernando Collor ${ }^{10}$ : primeiramente, ao apoiá-lo em sua candidatura à presidência em 1989, em que "o Jornal Nacional consagrou-o vitorioso no debate televisivo final" (Murilo Ramos, 2005, p. 145), e, depois, ao ficar contra o então presidente após o escândalo envolvendo corrupção no poder executivo. "A Globo, ao apoiar a saída de Collor, estava salvando o país da corrupção, porém não aludia ao fato de que tinha sido, também, responsável pela sua entrada, ajudando a construir o seu marketing de 'Caçador de Marajás"” (idem, p. 146).

No governo de Fernando Henrique - 1995-2002 - as Organizações Globo envolveram-se com o Estado dando apoio direto à política de privatizações, fato esse que vai ao encontro de seus posicionamentos econômicos neoliberais e que também serviu para conquistar, junto ao governo, um poder de barganha em futuras negociações político-econômicas. $\mathrm{O}$ apoio das Organizações Globo à política de privatizações, segundo Palha (2008), realizou-se a partir de seus jornais - impressos, rádio e televisivos - que apontavam, claramente, os possíveis ganhos que a população teria com as privatizações em termos de qualidade de serviços e como tais ações poderiam gerar ganhos para a economia do país. Além disso, a TV Globo cedeu atores e atrizes para campanhas institucionais pró-privatização, do governo federal, com o intuito de buscar credibilidade do público para tais ações. Em um programa específico, Globo Repórter, com o tema privatizações, Palha (2008) relata que um repórter foi até empresas privatizadas do setor de siderurgia e "em toda a narrativa o tom é o do otimismo. Empregados e administradores são unânimes em afirmar o dinamismo e as muitas vantagens angariadas com o processo de privatização" (p.308).

Todo esse empenho das Organizações Globo teria sua contrapartida cobrada do governo em dois episódios significativos. O primeiro tem relação com o endividamento adquirido pelas Organizações a partir de suas investidas no segmento de televisão a cabo, no final dos anos noventa. Tal endividamento, segundo Montuori e Amoroso (2010) e Miguel (2003) foi, de certa forma, sanado a partir de um repasse do BNDES - Banco Nacional de Desenvolvimento Econômico e Social - para a Globo, no valor de 284 milhões de reais, no ano de 2002. Segundo os autores, o repasse ocorreu sob críticas de segmentos da sociedade, principalmente, associações independentes de mídia. No entanto, o BNDES justificou o repasse como sendo uma ação de investimento em que tal quantia retornaria ao banco com juros corrigidos e lucros. O que não ocorreu.

O segundo episódio tem a ver, também, com a crise econômica por qual passava as Organizações Globo. No ano de 2001, segundo Cabral (2003), houve, na Câmara dos Deputados, uma Proposta de Emenda à Constituição ${ }^{11}$ que previa a "participação de capital estrangeiro na mídia brasileira" (p.09). Essa proposta obteve resistência, principalmente, de partidos políticos da oposição e do Fórum Nacional pela Democratização

10 Fernando Collor de Melo foi governador do Estado de Alagoas, de 1987 a 1989, e foi o candidato eleito à Presidência da República, em 1989 , pelo PRN - Partido da Reconstrução Nacional.

11 Segundo Cabral (2003), a emenda foi de autoria do deputado Henrique Alves (PMDB-RN), sendo que "a família de Alves é dona do jornal 'A Tribuna do Norte' e da 'TV Tabugi', afiliada da Rede Globo no Rio Grande do Norte" (p.07). 
da Comunicação, que se reuniu em Brasília, no final de 2001, para apontar críticas à emenda, tais como o fato dela levar a uma "submissão dos meios de formação de consciência nacional a perspectivas, consideradas estranhas ao interesse público" (p.10). Mesmo com tais resistências, a influência das Organizações Globo e de outros grupos de comunicação, como a Folha de São Paulo, o Estadão, o Grupo Abril e associações como a Associação Nacional de Jornais - ANJ e a Associação Brasileira de Emissoras de Rádio e Televisão - ABERT, resultou na sanção da Lei 10.610, pelo presidente Fernando Henrique Cardoso, em 20 de dezembro de 2002, abrindo $30 \%$ do capital da mídia brasileira para os estrangeiros.

Ainda no ano de 2002, segundo Miguel (2003), as Organizações Globo envolveram-se, novamente, em uma eleição presidencial ao apoiar o candidato de esquerda, Lula $^{12}$. Curiosamente, é o mesmo candidato que ela foi contra, em 1989, quando apoiou Collor. "Em 2002, porém, o clima entre o líder do Partido dos Trabalhadores e a maior emissora de televisão do país não era apenas cordial, era festivo" (p. 290).

Miguel (2003) afirma que, apesar de a relação das Organizações Globo com Lula ser uma incógnita, era de se esperar que ela apoiasse algum candidato que tivesse chance de ganhar em 2002. Fernando Henrique Cardoso, presidente na época em seu segundo mandato, não poderia mais se reeleger e José Serra era visto pelas Organizações como um candidato fraco à vitória, o que acabou resultando, então, no apoio a Lula.

Segundo Murilo Ramos (2005), esse "favor" dado pela $T V$ Globo a Lula foi recompensado no desmonte do projeto da Ancinav - Agência Nacional de Cinema e Audiovisual, por influência da emissora junto ao governo. O projeto dessa Agência aumentava a legislação sobre as televisões de concessão pública, podendo o Estado interferir na estrutura de programação de uma emissora, tal como a TV Globo. Porém, como já dito, o projeto foi derrubado.

Em outro caso, referente à cobertura do escândalo do mensalão, a Rede Globo, por meio do Jornal Nacional, criou-se uma espécie de conflito em que existiam o "bem" e o "mal". Segundo Guazina e Motta "o conflito (enquanto ingrediente básico do drama) funciona como elemento estruturador da narrativa jornalística, dualiza o mundo político e reforça a visão que compreende a política como um jogo de oposições" (2010, p. 146). O Jornal Nacional, então, colocou os acusados uns contra os outros, mas protegeu, ao não colocar em jogo, a integridade geral do governo Lula. Essa colocação quanto à Rede Globo pode ser reafirmada com base em uma pesquisa empírica feita com os principais jornais impressos do país, acerca da cobertura do mensalão em 2005: O Globo, Estadão e Folha de São Paulo. Nela se chegou à conclusão de que, principalmente, $O$ Globo culpabilizou os principais envolvidos no caso, porém, resguardou/desatrelou do escândalo a imagem de Lula e de seu governo (Coutinho; Miguel, 2007).

Mais recentemente, com relação às manifestações ocorridas em junho de 2013, Calil aponta que a $T V$ Globo "cuidadosamente buscou preservar o governo de Dilma Roussef das críticas mais violentas. Em especial as críticas aos enormes gastos com as obras da Copa do Mundo" (2013, p.11). A partir das discussões já tecidas nesse trabalho, pode-se afirmar que a atitude da $T V$ Globo é bastante coerente, pois ela já vinha há algum tempo apoiando o governo do Partido dos Trabalhadores. Além disso, ela foi uma das maiores detentoras, como indústria cultural, dos direitos de cobertura e exibição da Copa do Mundo e suas expectativas de lucro dependiam diretamente de uma boa aceitação popular, tanto da Copa como da forma que o governo a estava conduzindo. Então, houve uma grande parceria entre essa indústria cultural e o governo, além de empresas privadas envolvidas em investimentos milionários para a Copa do Mundo. O que caracteriza essa prática da $T V$ Globo como condizente a um aparelho privado de hegemonia.

Por fim, reitera-se que as práticas abordadas da $T V$ Globo a caracterizam como uma indústria cultural, por ser uma empresa que lida com a comunicação/arte a partir da lógica capitalista industrial do lucro e também por atingir um grande público, se relacionando com o mesmo enquanto massa (Alencar, 2004; Duarte, 2002; Ribeiro, Roxo, Sacramento, 2010). Funciona como um aparelho privado de hegemonia, a partir do conceito de Gramsci, visto que as relações que a $T V$ Globo vem desenvolvendo com o Estado são de parceria, proteção e disseminação de posicionamentos ideológicos compartilhados (Coutinho; Miguel, 2007; Miguel, 2003; Motta; Guazina, 2010; Murilo Ramos, 2005; Roberto Ramos, 2005).

\section{Globo Filmes - práticas de uma indústria hegemônica no cinema nacional}

A Globo Filmes foi criada em 1998 com o objetivo de ser o segmento cinematográfico da Rede Globo, para atuar no apoio à produção, distribuição e exibição de filmes nacionais que fossem de seu interesse. Por fazer parte de uma complexa indústria cultural, tal interesse foi/é influenciado, diretamente, pelas ideologias e práticas comerciais das Organizações Globo como um todo.

A segunda metade da década de 1990 caracterizou-se por um aumento na produção cinematográfica nacional, a partir da criação de leis que permitiam à 
iniciativa privada investir valores em filmes nacionais e deduzir tais valores de seu imposto de renda anual ${ }^{13}$. Segundo Butcher (2006) esse crescimento começou a se intensificar a partir de 1995 e manteve-se em ascendência. Esse fato chamou a atenção da Rede Globo para o mercado cinematográfico nacional, já que esse mostrava sinais de evolução e de que poderia se recuperar após o fechamento da Empresa Brasileira de Filmes ${ }^{14}$ - EMBRAFILME - pelo Presidente Collor em 1990. Então, a Rede Globo criou a Globo Filmes, em 1998, para se integrar melhor a essa nova tendência de mercado e, como em todos os seus outros segmentos de negócio, buscar o controle e hegemonia do mesmo.

Para a compreensão da influência da Globo Filmes no cinema nacional, é necessário conhecer a dinâmica de funcionamento da atividade cinematográfica. Bernardet (1985) a situa, na condição de indústria ${ }^{15}$, a partir da existência de três fases: a produção, a distribuição e a exibição.

A produção é a etapa em que o filme é feito por uma produtora, que, com ele pronto, tentará vendê-lo a uma distribuidora. A distribuição é a fase em que uma empresa distribuidora de cinema comprará uma cota de um filme, para poder pagar sua copiagem e disseminá-lo pelas salas de exibição. Essa cota dá direito à distribuidora de retirar parte dos lucros com a exibição do filme. Um filme, portanto, tem que ser financeiramente interessante para uma distribuidora. Existem diversas distribuidoras brasileiras, porém, as mais influentes, no território nacional, são multinacionais como a Warner, Fox, Paris Filmes, Sony e Paramount.

A exibição ocorre quando o filme vai para o cinema, ou seja, o circuito exibidor é formado por salas de cinemas. Como já visto, a distribuidora vai disseminar os filmes pelos exibidores, cinemas. Da mesma forma que as distribuidoras, há exibidoras multinacionais atuando no Brasil, tais como o Cinépolis, o Cinemark e a United Cinemas International Brasil.

O cinema brasileiro, diferentemente do americano, não é uma indústria. O que caracteriza o cinema como uma indústria, além de apresentar, em sua realização, as três fases descritas por Bernardet (1985), é o fato de ele possuir uma grande dinâmica no processo de realização/ exibição cinematográfica e, consequentemente, produzir/lançar um grande volume de filmes e obter uma significativa quantidade de público. Dessa forma, a indústria pode-se sustentar, principalmente, a partir da venda de ingressos, além das parcerias com empresas privadas que se divulgam nas obras e de incentivos estatais. O que mais se aproxima dessa realidade industrial no Brasil são os filmes realizados/apoiados pela Globo Filmes.

A Globo Filmes, segundo a descrição de seu diretor executivo no site da empresa, seção quem somos ${ }^{16}$, atua na produção - "apoio ao desenvolvimento artístico" e na divulgação de filmes nacionais - por meio da $T V$ Globo e em outras mídias, como rádio e internet, sendo que, segundo o site, os "investimentos na divulgação dos filmes nacionais permitiram que esses filmes pudessem competir com o cinema estrangeiro, dominante no país". Além disso, a Globo Filmes tem estratégias para exibição dos seus filmes também em janela televisiva.

Junto à Central Globo de Programação, temos estimulado a exibição dos filmes nacionais na $T V$ Globo - cerca de 80 produções são exibidas por ano. Hoje, a TV Globo é a TV aberta privada brasileira que mais exibe filmes nacionais das mais variadas vertentes (Globo Filmes, site, 2014, seção "quem somos”).

Segundo Fonseca (2003) e Silva (2010), realmente a Globo Filmes contribuiu para o aumento da exibição de filmes brasileiros no cinema nacional. Porém, deve-se ficar bastante atento a este fato, pois, segundo Fonseca:

O braço cinematográfico da Rede Globo está fazendo os filmes de maior audiência do cinema brasileiro, associando-se a sucessos como 'Carandiru' e 'Cidade de Deus', ou levando para a tela grande produtos televisivos como 'Os Normais' e 'Casseta e Planeta'. Isso gerou um novo domínio global, agora na indústria do cinema, onde só os filmes com a mídia da TV Globo conseguem decolar. (2003, p. 1)

Acrescentando ao que afirma Fonseca (2003), a Globo Filmes, devido à grande influência da TV Globo no contexto da comunicação nacional, tem acesso fácil

13 Lei Rouanet - Lei n 8.313/1991, que permitia empresas deduzirem até 4\% de seu imposto devido em atividades culturais, incluindo o cinema Lei do Audiovisual - Lei n 8685/93 tem mecanismo semelhante à Lei Rouanet, porém, é voltada a atividades audiovisuais.

14 A Embrafilme, segundo Paiva (2006), foi uma empresa criada durante a ditadura militar, em 1969, e era responsável pela produção, distribuição e apoio a exibição de filmes nacionais. O autor ressalta que tal empresa funcionou como um aparelho ideológico do estado, segundo definição de Althusser (1985), e que, durante o período de maior censura da ditadura militar - 1969 até o início dos anos 1980 - ela só produzia filmes que passassem pelo crivo ideológico da própria ditadura. Com o abrandamento da censura, a partir dos anos 1980, a Embrafilme continuou a produzir filmes, agora, livre dos processos de censura aos mesmos. Entretanto, a empresa foi fechada, em 1990, pelo Presidente Collor, o que ocasionou uma queda brutal na produção e exibição cinematográfica nacional.

15 O conceito de "indústria", em Bernadet (1985), não se refere ao conceito de indústria cultural, pois o autor não se baseia na perspectiva de Adorno e Horkheimer. Quando Bernadet (1985) se refere a "indústria", de cinema, está relacionando esta à atividade cinematográfica como explicado no texto, composta de três etapas distintas.

16 http://globofilmes.globo.com/quemsomos.htm, acesso em 08/2014 
e boa relação com as distribuidoras e exibidoras nacionais e internacionais, influenciando, junto a estes, a entrada de filmes brasileiros no circuito de exibição. Esses filmes, devido à grande divulgação na programação da TV Globo, em programas como Domingão do Faustão, Mais Você, Big Brother Brasil e até mesmo dentro das novelas, tendem a ser grande sucesso de bilheteria, como os recentes De pernas pro ar 1 e $2(2011,2012)$, Até que a sorte nos separe (2012) e Minha mãe é uma peça (2013) ${ }^{17}$. Soma-se a esse sucesso o fato de os atores da maioria desses filmes serem conhecidos pelo público por suas atuações na televisão, o que ajuda ainda mais na divulgação e, consequentemente, num possível aumento do número de espectadores.

A produção de filmes pela Globo Filmes, ou com seu nome envolvido desde a etapa de produção, facilita a captação de recursos, viabilizando mais rapidamente as filmagens e finalizações dos filmes. Atualmente, no Brasil, como abordado, há leis de incentivo que permitem o investimento privado na produção filmica. Consequentemente, quando um projeto de filme busca recursos com empresas e já tem o apoio formal da Globo Filmes, os processos podem-se tornar mais fáceis.

De acordo com Barone (2009), alguns filmes são produzidos por meio da lei de incentivo, sem estar envolvidos com a Globo Filmes, porém, não chegam aos cinemas por não conseguirem espaço frente às distribuidoras e exibidoras que, como já dito, são em sua maioria internacionais. A conclusão desse raciocínio é simples e remete novamente a Fonseca (2003): somente filmes que tenham alguma relação com a Globo Filmes "conseguem decolar", ou seja, completar o tripé cinematográfico de produção, distribuição e exibição e, assim, podem tentar um bom quantitativo de público.

Segundo Borges (2014), de 1998 a 2013, cinquenta e sete filmes brasileiros tiveram mais de um milhão de espectadores. Desse conjunto de filmes, apenas cin$\mathrm{CO}^{18}$, não foram produzidos ou coproduzidos pela Globo Filmes. E, mais recentemente, os três filmes ${ }^{19}$ com maior bilheteria dos anos 2011,2012 e 2013, respectivamente, também tiveram apoio da Globo Filmes. A autora atribui isso às facilidades de divulgação dos filmes, na própria $T V$ Globo, e a utilização de estrelas do próprio canal. Pode-se acrescentar a isso, também, como apontado, as facilidades de negociação que os filmes passam a ter, com o apoio da Globo Filmes, nas etapas de produção, distribuição e exibição.
Apesar do aumento de público dos filmes nacionais, ainda não se pode afirmar que o Brasil já possua uma indústria cinematográfica, pois a quantidade de filmes nacionais presentes no cinema brasileiro, frente aos filmes estrangeiros, ainda é inferior; tanto quanto a quantidade de espectadores de filmes brasileiros frente aos de produções estrangeiras. Segundo dados da Agência Nacional do Cinema ${ }^{20}$ - ANCINE - foram lançados 387 filmes no ano de 2014, sendo 114 o número de lançamentos de filmes nacionais. E, quando se trata de número de espectadores, nota-se que, do total de 155,6 milhões de espectadores, 19 milhões são de filmes brasileiros, o que corresponde a apenas $12,2 \%$ de participação no total de espectadores, segundo o informe anual de exibição da ANCINE ${ }^{21}$ sobre 2014.

Apesar, então, de não haver uma indústria cinematográfica brasileira consolidada, pode-se observar que há uma indústria cultural que está monopolizando a atividade cinematográfica e buscando hegemonizar seus processos com a finalidade de lucro. Utilizando-se de seus crivos ideológicos para escolher e apoiar o que entrará ou não no cinema e o que poderá fazer ou não sucesso de público.

\section{Considerações finais}

Esse artigo se propôs a analisar algumas práticas da Tv Globo e da Globo Filmes a partir dos conceitos de indústria cultural, hegemonia e aparelho privado de hegemonia. Para tanto, iniciou-se o trabalho com uma breve apresentação de tais conceitos, relacionando-os. A partir disso, foi traçado um panorama histórico de práticas da Tv Globo, desde sua criação, em 1965, até os dias atuais, vislumbrando as principais iniciativas dessa empresa e suas relações com o Estado. Concluiu-se que suas práticas a caracterizam como uma indústria cultural por ser um meio de comunicação de massa que tem como finalidade principal o lucro. Para isso, a $T v$ Globo realiza parcerias comerciais com outras indústrias e trabalha seus conteúdos com a intenção de atingir uma massa e gerar/fomentar uma cultura de massa. Os conteúdos realizados para essa massa têm a intenção de fidelizá-la a seus produtos culturais e a seus posicionamentos ideológicos e de seus parceiros. Discutiu-se, também, que a Tv Globo/Organizações Globo, em sua trajetória, já realizou diversas parcerias com o Estado,

17 Segundo dados da Agência Nacional do Cinema - ANCINE - os públicos dos filmes citados, nos cinemas, foram: De pernas pro ar (2011) - 3.095.894 espectadores. De pernas pro ar 2 (2012) - 4.2 milhões de espectadores. Até que a sorte nos separe (2012): 3,3 milhões de espectadores. Minha mãe é uma peça (2013) - 4,6 milhões de espectadores.

18 Xuxa Requebra (1999), Xuxa Popstar (2000), Tropa de Elite (2007), Bruna Surfistinha (2010), Somos Tão Jovens (2013).

19 De pernas pro ar (2011), Até que a sorte nos separe (2012), Minha mãe é uma peça (2013).

$20 \mathrm{http} / / /$ oca.ancine.gov.br/media/SAM/DadosMercado/2116-22052015.pdf

21 http://www.ancine.gov.br/sala-imprensa/noticias/ancine-divulga-informe-anual-preliminar-do-mercado-de-exibi-o-em-2014 
em que houve trocas de favores, principalmente relacionados a questões legislativas, que beneficiaram essa indústria cultural, e a formas de abordagens midiáticas de ações governamentais que favoreceram o Estado.

Quanto a Globo Filmes, segmento cinematográfico das Organizações Globo, abordou-se sua criação como estratégia econômica dessa indústria cultural para participar mais diretamente do crescimento do cinema nacional que vinha ocorrendo a partir da segunda metade da década de 1990 com a implementação das leis de incentivo.A Globo Filmes passou a atuar no apoio a produção e distribuição de filmes. Principalmente agregando valor a projetos na etapa de captação de recursos, junto a empresas, e mediando processos com distribuidoras. Além disso, a Globo Filmes facilitou/facilita burocracias contratuais de participações de elencos da Tv Globo em produções que ela apoiava/apoia e negociou/negocia também, junto a essa, espaços para divulgação de filmes em sua programação. Com todas essas iniciativas, rapidamente, a Globo Filmes tornou-se hegemônica no que diz respeito à participação em filmes nacionais que chegam ao circuito de cinemas e, principalmente, aos filmes brasileiros de grande bilheteria. Em que tais filmes tiveram algum tipo de apoio da Globo Filmes e seu selo agregado às suas realizações.

Encerra-se esse artigo reiterando-se e chamando a atenção para as práticas da Tv Globo e da Globo Filmes como práticas hegemônicas de uma indústria cultural e de um aparelho privado de hegemonia, a Rede Globo, da qual essas duas empresas fazem parte. Suas práticas não estão apenas no espaço da cultura ou do entretenimento e caminham, muitas vezes sem chamar atenção, por instâncias e decisões políticas, econômicas e sociais nas quais fazem valer seus interesses ideológicos/econômicos. Acredita-se que a discussão de suas práticas pelos vieses/conceitos aqui apresentados possam possibilitar abordagens mais complexas de suas estratégias culturais e econômicas no intuito de se possibilitar a criação de táticas contra hegemônicas a essa poderosa indústria cultural. Objetiva-se, assim, se democratizar as práticas midiáticas brasileiras e se diminuir/acabar com as influências dessa indústria como aparelho privado de hegemonia.

\section{Referências}

ADORNO, Theodor; HORKHEIMER, Max. Indústria cultural e Sociedade. São Paulo: Editora Paz e Terra, 2009.

, M. Dialética do esclarecimento. Rio de Janeiro: Zahar, 1985.

ALENCAR, Mauro. A Hollywood brasileira - Panorama da telenovela no Brasil. Rio de Janeiro: Editora Senac-Rio, 2004. ALTHUSSER, Louis. Aparelhos ideológicos do Estado. Rio de Janeiro: Editora Graal, 1985.

ATÉ QUE A SORTE NOS SEPARE - Direção: Roberto
Santucci - Ficção - 104 min - Globo Filmes, Paris Filmes Brasil - 2012.

BARBOSA, Marialva Carlos. Imaginação televisual e os primórdios da TV no Brasil. In: RIBEIRO, Ana Paula Goulart; SACRAMENTO, Igor; ROXO, Marcos (org.). História da televisão no Brasil: do início aos dias de hoje. São Paulo: Contexto, 2010.

BARONE, João Guilherme. Exibição, crise de público e outras questões do cinema brasileiro. In: Revista Eletrônica Diversidade Cinematográfica-PUC-RS, Porto Alegre, 2009. Disponível em: <http://revistaseletronicas.pucrs.br/ojs/index.php/ famecos/article/viewFile/ 4980/3682>.Acesso em:jul. 2014. BERNADET, JeanClaude. O que é o cinema. São Paulo: Ed. Brasiliense, 1985.

BORGES, Danielle. A Produção Cinematográfica Brasileira (1995-2013) e o Atual Modelo de Políticas Públicas para o Cinema Nacional. In: CONGRESSO BRASILEIRO DE CIÊNCIAS DA COMUNICAÇÃO, 2014. Foz do Iguaçu. Anais 2014. São Paulo: Intercom, 2014.

BUTCHER, Pedro. A dona da história: origens da Globo Filmes e seu impacto no audiovisual brasileiro. Dissertação (Mestrado em Comunicação). Universidade Federal do Rio de Janeiro, 2006.

CABRAL, Eula Dantas Taveira. Capital estrangeiro na mídia brasileira: salvação ou desgraça? In: CONGRESSO BRASILEIRO DE CIÊNCIAS DA COMUNICAÇÃO, 2003. Belo Horizonte. Anais 2003. São Paulo: Intercom, 2003.

CALABRE, Lia. A era do rádio. Rio de Janeiro: Zahar, 2002.

CALIL, Gilberto Grazzi. Embates e disputas em torno das jornadas de junho. Projeto História - Revista do Programa de Estudos Pós-Graduados de História, v. 47. São Paulo, 2013. Disponível em:

http://revistas.pucsp.br/index.php/revph/article/ view/17155. Acesso em: ago. 2014.

CLARK, Walter. O campeão de audiência. Rio de Janeiro: Best Seller, 1991.

COELHO, Teixeira. O que é Indústria cultural. São Paulo: Editora Brasiliense, 1980.

COUTINHO, Aline de Almeida; MIGUEL, Luis Felipe. A crise e suas fronteiras: oito meses de "mensalão" nos editoriais dos jornais. Revista Opinião Pública, Campinas, v. 13, n. 01.2007.

DUARTE, Rodrigo. A estética e a discussão sobre indústria cultural no brasil. Revista Ideias, v. 1, n.4. Campinas, 2012. Disponível em:

$<$ http://www.ifch.unicamp.br/ojs/index.php/ideias/article/view/858>. Acesso em: jul. 2014.

GATTI, André Piero. Distribuição e exibição na indústria cinematográfica brasileira (1993-2003). 2005. Tese (Doutorado em Artes). - Universidade de Campinas, Instituto de Artes. 2005.

GRAMSCI, Antônio. Cadernos do cárcere: temas de cultura. Ação Católica. Americanismo e fordismo. Rio de Janeiro: Civilização Brasileira, 2001.

- Cadernos do cárcere: introdução ao estudo da filosofia. A filosofia de Benedetto Croce. Rio de Janeiro: Civilização Brasileira, 1999. 
GRUPPI, Luciano. Conceito de Hegemonia em Gramsci. Rio de Janeiro, Edições Graal, 1978.

GUAZINA, Liziane; MOTTA, Luiz. O conflito como categoria estruturante da narrativa política - o caso do Jornal Nacional. Brazilian Journalism Research, vol. 06, n.01. Brasília, 2010. Disponível em: <http://www.bjr.libertar.org/index. php/bjr/article/viewFile/ 251/250>. Acesso em: ago. 2014. FONSECA, Rodrigo. O poder da Globo Filmes no cinema brasileiro. Revista Brasileira de Cinema, 2003. Disponível em: $<$ www.revistadecinema.com.br>. Acesso em jul. 2014.

HUPFER, Maria Luisa R. As rainhas do rádio: símbolos da nascente Indústria cultural brasileira. São Paulo: Senac Editora, 2009.

INEP. Instituto Nacional de Estudos e Pesquisas Educacionais Anísio Teixeira. Mapa do analfabetismo no Brasil, 2003. Disponível em: http://www.oei.es/quipu/brasil/estadisticas/analfabetismo2003.pdf. Acesso em agosto de 2015.

MIGUEL, Luis Felipe. A eleição visível: a Rede Globo descobre a política em 2002. DADOS - Revista de Ciências Sociais, Rio de Janeiro, v. 46, n.2, 2003.

MONTUORI, Carla Montuori; AMOROSO, Patricia Rodelli. Entre a realidade e a ficção: os desacertos da política neoliberal no jornal nacional. Revista de Educação, Cultura e Comunicação, Lorena, v. 1, n. 2, 2011.

MORAES, Dênis. Comunicação, Hegemonia e Contra-Hegemonia: a contribuição teórica de Gramsci. Revista Debates, v.4, n.1. Porto Alegre, 2010. Disponível em: <http://seer.ufrgs.br/ index.php/debates/article/view/12420>.Acesso em:jul. 2014. ORTIZ, Renato. A escola de Frankfurt e a questão da cultura. Revista Brasileira de Ciências Sociais, 1986.

PAIVA, Claudio. O cinema de Hollywood e a invenção da América: Mídias e interculturalidades locais e globais. In: Bocc - Biblioteca on-line de ciências da comunciação, 2006. Disponível em: <http://www.bocc.ubi.pt/pag/paiva-claudio-hollywood-invencao-america.pdf>. Acesso em: jul. 2014.

PALHA, Cássia Louro. A Rede Globo e o seu Repórter: imagens políticas de Teodorico a Cardoso. Tese de Doutorado (Doutorado em História). Niterói: UFF, 2008.

PIERANTI, Octávio Penna. Políticas para mídia: dos militares ao governo Lula. Revista Lua Nova, São Paulo, v. 68, 2006.
RAMOS, Murilo César. A força de um aparelho privado de Hegemonia. In: CONGRESSO BRASILEIRO DE CIÊNCIAS DA COMUNICAÇÃO, 2005. Rio de Janeiro. Anais 2005. São Paulo: Intercom, 2005.

RAMOS, Roberto José. Rede Globo e ditadura militar: atualização histórica e ideologia. Revista Humanidades, Fortaleza, v. 20, n. 2, 2005.

RIBEIRO, Ana Paula Goulart; ROXO, Marco; SACRAMENTO, Igor. História da televisão no Brasil. São Paulo: Contexto, 2010.

SAROLDI, Luís Carlos. O rádio e a música. Revista USP. São Paulo, n.56, 2003.

SILVA, Hadija Chalupe. O filme nas telas: distribuição do cinema nacional. São Paulo:Terceiro Nome, 2010.

SODRÉ, Nelson Werneck. História da imprensa no Brasil. Rio de Janeiro: Mauad, 1999.

\section{Filmografia}

BRUNA SURFISTINHA - Direção: Marcus Baldini Ficção - 109min - Tv Zero - Imagem Filmes - 2010.

DE PERNAS PRO AR - Direção: Roberto Santucci Ficção - 101 min - Globo Filmes, Morena Filmes, Paris Filmes - Brasil - 2010

DE PERNAS PRO AR 2 - Direção: Roberto Santucci - Ficção - 99 min - Globo Filmes, Telecine, Paris Filmes Brasil - 2011

MINHA MÃE É UMA PEÇA - Direção: André Pellenz Ficção - 84 min - Globo Filmes, Paris Filmes - Brasil - 2013.

SOMOS TÃO JOVENS - Direção: Antônio Carlos da Fontoura - Ficção - 104min - Imagem Filmes - Fox Films - 2013. TROPA DE ELITE - Direção: José Padilha - Ficção 115min - Zazen Produções - Universal Pictures - 2007.

XUXA REQUEBRA - Direção: Tizuka Yamazaki - Ficção - 92 min - Xuxa Produções - Brasil - 1999

XUXA POP STAR - Direção: Paulo Sérgio de Almeida e Tizuka Yamazaki - Ficção - 90 min - Xuxa Produções Brasil - 2000

\section{Tv Globo and Globo Filmes: economic practices and relations with the State from the perspectives of cultural industry and hegemony}

\footnotetext{
Abstract

The aim of this study is to analyze some practices from Tv Globo and Globo Filmes, TV and cinema branches of Rede Globo, starting with the concepts of cultural industry, hegemony and private apparatus of hegemony. As for TV Globo, was traced a historical overview to analyze the economic strategies, that allowed it to become a hegemonic cultural industry, but also to discuss its relations with the State, facts which make possible the characterization as private apparatus of hegemony. As for Globo Filmes, was discussed the strategies related to production and distribution of national films that aimed to make it hegemonic regarding the contemporary brazilian cinematographic activity .
}

Keywords: Tv Globo; Globo Filmes; Cultural Industry; Hegemony; Private apparatus of Hegemony. 


\section{TV Globo y Globo Filmes: prácticas económicas y relaciones con el Estado a partir de las perspectivas de la industria y la hegemonía cultural}

\section{Resumen}

El objetivo de este trabajo es analizar algunas prácticas de TV Globo y Globo Filmes, televisión abierta y productora de cine de la Rede Globo, desde los conceptos de la industria cultural, la hegemonía y el aparato privado de la hegemonía. En cuanto a la TV Globo, se establece una visión histórica para analizar sus estrategias económicas, lo que permite ser una industria cultural hegemónica, como para discutir su relación con el Estado, esto hace que sea posible su caracterización como un aparato privado de la hegemonía. En cuanto a Globo Filmes, se discuten las estrategias relacionadas con la producción y distribución cinematográfica nacional que tiene como objetivo que sea hegemónica en relación con la actividad cinematrofráfica brasileña.

Palabras clave:Tv Globo; Globo Filmes; Industria Cultural; Hegemonía; Aparato Privado de Hegemonía

Data de recebimento: $04-10-2014$

Data de aceitação: 15 - 03 - 2015 